Article

\title{
The Effect of Carbon Nanofibers Surface Properties in Hydrogenation and Dehydrogenation Reactions
}

\author{
Stefano Cattaneo ${ }^{1}\left(\mathbb{D}\right.$, Felipe J. Sanchez Trujillo ${ }^{2}$, Nikolaos Dimitratos ${ }^{3}\left(\mathbb{C}\right.$ ) and Alberto Villa ${ }^{1, *(D)}$ \\ 1 Dipartimento di Chimica, Università degli Studi di Milano, Via Golgi 19, I-20133 Milano, Italy; \\ stefano.cattaneo2@unimi.it \\ 2 Cardiff Catalysis Institute, School of Chemistry, Cardiff University, Park Place, Cardiff CF10 3AT, UK; \\ Felipesancheztrujillo@gmail.com \\ 3 Dipartimento di Chimica Industriale "Toso Montanari", Università degli Studi di Bologna, \\ Viale Risorgimento 4, 40136 Bologna, Italy; Nikolaos.dimitratos@unibo.it \\ * Correspondence: alberto.villa@unimi.it.it; Tel.: +39-0250-314-361
}

Received: 29 October 2019; Accepted: 21 November 2019; Published: 23 November 2019

\begin{abstract}
In this study, carbon nanofiber-supported Pd nanoparticles were used in the hydrogenation of cinnamaldehyde and in the dehydrogenation of cinnamyl alcohol. The different graphitisation of the surface of the nanofibers and the amount of oxygen functionalisation significantly affected both activity and selectivity to the various reaction products. In particular, a decrease in nanoparticle dimensions and oxygen content resulted in an increase in overall activity for both of the studied reactions. Moreover, the selectivity to hydrocinnamaldehyde enhanced with increasing surface oxygen content in the cinnamaldehyde hydrogenation, while the selectivity to cinnamaldehyde was higher with low-functionalised nanofibers in the cinnamyl alcohol dehydrogenation. Finally, the most active catalyst proved also to be stable in consecutive runs.
\end{abstract}

Keywords: palladium; carbon nanofibers; cinnamaldehyde; hydrogenation; cinnamyl alcohol; dehydrogenation

\section{Introduction}

Carbon nanofibers (CNFs) were observed for the first time in 1889 from the decomposition of an organic gas at high temperature [1]. However, it was not until the last three decades that CNFs attracted considerable attention due to their chemical and physical properties, such as high thermal and electrical conductivity, high mechanical strength and good chemical resistance [2]. Nowadays, CNFs find application in the production of gas sensors and other electronic components, as polymer additive and as drug delivery systems as well [3-7]. On the other hand, one of the most promising applications of CNFs is in heterogeneous catalysis as support for metal nanoparticles. Their versatility is due to the ease of modification of some physiochemical properties, such as surface area, porosity and surface chemistry $[3,7,8]$. For example, the external surface of CNFs can be functionalised with many $\mathrm{O}-, \mathrm{N}-$, or $\mathrm{P}$-containing groups that can improve their dispersion in a broad range of solvents as well as increase the interaction with metal nanoparticles or organic molecules [9-13].

Many chemical reactions of industrial relevance benefit from the use of CNFs when used as support $[14,15]$. Better spreading of the metal on the support surface was observed when CNFs were used, leading to higher activity and selectivity compared to the other supports. The reason for the better spreading was attributed to higher metal-support interaction between the metal and the graphitic surface of the CNFs and to withdrawing properties of the functional groups on the CNFs surface [16].

The selective hydrogenation of $\alpha, \beta$-unsaturated aldehydes is an important reaction from an industrial point of view. Cinnamaldehyde, in particular, is one of the most significant fragrance 
aldehydes, with an estimated production of $1.5 \mathrm{kton} / \mathrm{year}$ via base-catalysed condensation of benzaldehyde and acetaldehyde [17]. The products of hydrogenation of the vinyl $(\mathrm{C}=\mathrm{C})$ or carbonyl $(\mathrm{C}=\mathrm{O})$ group, hydrocinnamaldehyde $(\mathrm{HCAL})$ or cinnamyl alcohol $(\mathrm{COH})$ respectively, are largely used in the production of various fine chemicals for the pharmaceutical and perfumery industry $[17,18]$. To selectively hydrogenate either the vinyl or the carbonyl group, several supported noble metal nanoparticles can be used, such as $\mathrm{Au}, \mathrm{Pd}, \mathrm{Pt}, \mathrm{Rh}, \mathrm{Ru}$ and $\mathrm{Ir}[19,20]$. Carbon-based supports, in particular, are reported to be very active for this specific reaction [21-23]. Pd nanoparticles supported on CNFs have shown to be more active and selective towards HCAL than activated carbon due to the high external surface area and the absence of microporosity that can cause mass transfer limitation [24]. De Jong et al. extensively studied the metal particle size and surface oxygen content effects for $\mathrm{Pt}$ and $\mathrm{Ru}$ nanoparticles supported on CNFs $[25,26]$. In their work, the authors showed how the absence of oxygen functionalities allows the adsorption of the benzene ring on the CNFs surface, thus increasing the selectivity towards HCAL but decreasing the overall activity. On the other hand, small nanoparticles are more active and selective towards $\mathrm{COH}$ due to the metal-benzene ring repulsion that makes the $\mathrm{C}=\mathrm{C}$ hydrogenation difficult [27].

On the other hand, the reverse reaction (cinnamyl alcohol dehydrogenation), is a typical example of an oxidation reaction of aromatic allylic alcohol [28-30]. The selective aerobic oxidation of alcohols is an important reaction in organic chemistry and the search for an active, selective and stable heterogeneous catalyst for this type of reactions from both an academic and industrial point of view is still a challenge [31,32]. The main product derived from the oxidation of cinnamyl alcohol is cinnamaldehyde. As already mentioned, cinnamaldehyde is widely used in the food and perfume industry, and its synthesis still involves chemical platforms derived from fossil fuels such as benzaldehyde and acetaldehyde [17]. Apart from cinnamaldehyde, the coexistence of a hydroxyl group and an alkenyl group confers to cinnamyl alcohol high reactivity, leading to a complicated reaction pathway with many by-products that can be produced. Hydrocinnamyl alcohol $(\mathrm{HCOH})$ and 1-phenyl-1-propene (PPE) are the two main by-products derived from hydrogenation and hydrogenolysis reactions respectively. The nature of the catalyst and the reaction conditions play a crucial role in directing the selectivity of the reaction. Supported metal nanoparticles are usually employed for the selective conversion of $\mathrm{COH}$ into $\mathrm{CAL}$, and among all, $\mathrm{Pd}$ is one of the most used active metal for oxidation reaction, despite often suffering from deactivation phenomena [33-38].

In this study, Pd nanoparticles were supported by the impregnation method on four CNFs with a different order of graphitisation, oxygen content and particle dimension, namely CNFs-PS, CNFs-PS-OX, CNFs-LHT and CNFs-HHT. The catalysts were then thoroughly characterised with X-ray photoelectron spectroscopy (XPS), Raman spectroscopy, transmission electron microscopy (TEM) and energy-dispersive X-ray spectroscopy (EDX) in order to correlate nanoparticles dimension and dispersion with the surface properties of the CNFs. The catalytic performances of the synthesised catalysts were evaluated on two Pd-catalysed reactions, namely cinnamaldehyde hydrogenation and cinnamyl alcohol oxidation. Our final goal was to study how the graphitisation order and surface oxygen content of the CNFs influence the catalytic activity in the two proposed reactions.

\section{Materials and Methods}

\subsection{Catalyst Preparation}

Vapour-grown carbon nanofibers CNFs PR24-PS, PR24-LHT and PR24-HHT were purchased from Applied Sciences, Inc. (Cedarville, OH, USA). CNFs PR24-PS was treated at $700{ }^{\circ} \mathrm{C}$ (pyrolytically striped), PR24-LHT at $1500^{\circ} \mathrm{C}$ and PR24-HHT at $3000^{\circ} \mathrm{C}$. A detailed characterisation of these materials can be found in a previous report [39].

The CNFs-PS-OX support was prepared by oxidation treatment with $\mathrm{HNO}_{3}$ of the commercial CNFs-PS following the procedure reported elsewhere [40]. Typically, $2 \mathrm{~g}$ of CNFs-PS were added to a 
concentrated solution of $\mathrm{HNO}_{3}(1 \mathrm{~L}, 70 \%)$ and stirred for $2 \mathrm{~h}$ at $100{ }^{\circ} \mathrm{C}$. The oxidised $\mathrm{CNF}$ s were then filtered, washed with distilled water and dried at $80^{\circ} \mathrm{C}$ for several hours.

All the Pd supported catalysts were prepared with an incipient wetness impregnation method followed by chemical reduction in order to have a theoretical metal loading of $1 \mathrm{wt} \%$. In a typical $1 \mathrm{~g}$ preparation, the appropriate amount of CNFs support $(0.99 \mathrm{~g})$ was added to a $100 \mathrm{~mL}$ aqueous solution of $\mathrm{Na}_{2} \mathrm{PdCl}_{4} \cdot 2 \mathrm{H}_{2} \mathrm{O}$ (Pd: $0.094 \mathrm{mmol}$; metal precursor purchased from Sigma-Aldrich, Haverhill, MA, USA, $\geq 99.99 \%$ ) and the solution was vigorously stirred at room temperature for $6 \mathrm{~h}$. A freshly prepared aqueous solution of $\mathrm{NaBH}_{4}\left(0.1 \mathrm{M}, \mathrm{NaBH}_{4} / \mathrm{Pd}(\mathrm{mol} / \mathrm{mol})=8\right.$; purchased from Sigma-Aldrich, $\left.99.99 \%\right)$ was then added and the solution was left stirring for an additional $6 \mathrm{~h}$. Finally, the catalyst was filtered, washed thoroughly several times and dried at $80^{\circ} \mathrm{C}$ for $2 \mathrm{~h}$.

\subsection{Catalysts Characterisation}

X-ray diffraction (XRD) analysis was performed with a PANalytical X'PertPROX-ray diffractometer using a $\mathrm{Cu} \mathrm{K} \alpha$ radiation source $\left(\lambda=1.5418 \mathrm{~A}^{\circ}\right)$ and operated at $40 \mathrm{kV}$ and $30 \mathrm{~mA}$. The diffraction patterns were collected over the $10-80^{\circ} 2 \theta$ range at a step size of $0.017^{\circ}$.

X-ray photoelectron spectroscopy (XPS) data were collected with a Thermo Scientific K-alpha ${ }^{+}$ spectrometer equipped with a monochromatic Al X-ray source operating at $72 \mathrm{~W}(6 \mathrm{~mA} \times 12 \mathrm{kV})$, and with the signal averaged over an oval-shaped area of approximately $600 \times 400$ microns. The data were recorded at pass energies of $40 \mathrm{eV}$ for high-resolution scans and $150 \mathrm{eV}$ for survey scans, with a $0.1 \mathrm{eV}$ and $1 \mathrm{eV}$ step size respectively. Charge neutralisation of the sample was achieved using a combination of both low energy electrons and argon ions (less than $1 \mathrm{eV}$ ) which gave a $\mathrm{C}(1 \mathrm{~s})$ binding energy of $284.8 \mathrm{eV}$. The envelopes were fitted after subtraction of a Shirley background using CasaXPS (v2.3.17 PR1.1) using Scofield sensitivity factors and an energy exponent of -0.6 .

Bare supports, fresh and used catalysts were analysed by Raman spectroscopy with a Renishaw inVia Raman microscope. Typically, $0.01 \mathrm{~g}$ of sample was analysed under an IR class laser $(514 \mathrm{~nm})$ with a laser intensity of $50 \%$ and scanned at an attenuation time of $22 \mathrm{~s}$ and 10 scans.

Transmission electron microscopy (TEM) analysis was carried out using a JEOL JEM 2100 TEM operating at $200 \mathrm{kV}$. The samples were firstly dispersed in absolute ethanol and sonicated for $5 \mathrm{~min}$. A drop of this suspension was placed on a holey carbon film supported by a 300 mesh copper grid. Mean particle sizes and particle size distributions were obtained by measuring the size of over 500 particles from different areas.

Pd surface atoms abundance was calculated assuming that all nanoparticles had cuboctahedral morphology with the cubic close-packed structure in this size range; the full calculation of the number of surface-exposed atoms is reported in the Supplementary Information.

To study the morphology of the samples and determine the Pd content, scanning electron microscope (SEM) images were taken on a Hitachi TM3030PLUS equipped with a Quantax70 energy-dispersive X-ray spectroscope (EDX).

\subsection{Catalytic Reactions}

Cinnamaldehyde hydrogenation was performed at $25^{\circ} \mathrm{C}$, using a stainless steel batch reactor (100 mL capacity), equipped with heater, magnetic stirrer, gas supply system and thermocouple. Cinnamaldehyde solution ( $15 \mathrm{~mL} ; 0.3 \mathrm{M}$ in xylene, purchased from Sigma-Aldrich, $>99 \%$ ) was added into the reactor and the desired amount of catalyst (substrate: catalyst molar ratio $=1000$ ) was suspended in the solution. The $\mathrm{H}_{2}$ pressure was set to one bar as an optimised reaction condition while avoiding the mass transport issue. The mixture was heated to the reaction temperature, $25^{\circ} \mathrm{C}$, and stirred at $1250 \mathrm{rpm}$.

Cinnamyl alcohol dehydrogenation was performed at $100{ }^{\circ} \mathrm{C}$, using a stainless-steel batch reactor (100 mL capacity), equipped with heater, magnetic stirrer, gas supply system and thermocouple. Cinnamyl alcohol solution ( $15 \mathrm{~mL} ; 0.3 \mathrm{M}$ in xylene, purchased from Sigma-Aldrich, $>99 \%$ ) was added into the reactor and the desired amount of catalyst (substrate: catalyst molar ratio $=500$ ) was suspended 
in the solution. The $\mathrm{N}_{2}$ pressure was set to 3 bar as optimised reaction condition while avoiding mass transport issue. The mixture was finally heated to the reaction temperature, $100{ }^{\circ} \mathrm{C}$, and stirred at $1250 \mathrm{rpm}$.

During the reaction, samples were removed periodically $(0.2 \mathrm{~mL})$ and identification of the products was performed using a Thermo Scientific Trace ISQ QD Single Quadrupole GC-MS (Thermo Scientific, Waltham, MA, USA) equipped with a capillary column HP- $30 \mathrm{~m} \times 0.32 \mathrm{~mm}, 0.25 \times \mathrm{m}$ Film, by Agilent Technologies. Quantitative analysis with an external standard method (n-octanol; Sigma-Aldrich, $\geq 99 \%$ ) was used. At the end of the reaction, the autoclave was cooled to room temperature, the $\mathrm{H}_{2}$ flow stopped and the autoclave purged with flowing nitrogen. Recycling tests were carried out under the same experimental conditions. The catalyst was recycled in the subsequent run after filtration without any further treatment.

\section{Results}

\subsection{Catalysts Characterisation}

The three commercial supports (CNFs-PS, CNFs-LHT and CNFs-HHT) consist in hollow fishbone fibres with an average diameter of $80 \pm 30 \mathrm{~nm}$ and a specific surface area of around $50 \mathrm{~m}^{2} \mathrm{~g}^{-1}$. In particular, CNFs-PS are pyrolitically stripped fibre, with a thin chemically vapour deposited (CVD) layer of carbon over a graphitic fishbone core; the pyrolitical stripping step allows to remove any polyaromatic hydrocarbons from the fibre surface, leaving a thin surface layer of amorphous carbon. The CNFs-LHT are fibre treated at a temperature of $1500{ }^{\circ} \mathrm{C}$ to ensure complete carbonisation of any surface $\mathrm{CVD}$ carbon. The CNFs-HHT are high temperature treated fibres $\left(300{ }^{\circ} \mathrm{C}\right)$ with the surface CVD carbon layer fully graphitised. Finally, the CNFs-PS-OX are the commercial CNFs-PS fibres treated with $\mathrm{HNO}_{3}$ in order to introduce oxygen functional groups.

X-ray photoelectron spectroscopy (XPS) analysis was conducted on fresh and used samples to determine their electronic states and evaluate the metal surface abundance. From the deconvolution of the $\mathrm{C} 1$ s peak, it is possible to measure the concentration of $\mathrm{sp}^{2}$ (Binding Energy, B.E. ca. $284 \mathrm{eV}$ ) and $\mathrm{sp}^{3}$ (B.E. ca. $285 \mathrm{eV}$ ) hybridisation of the CNFs supports [39]. The ratio $\mathrm{sp}^{2} / \mathrm{sp}^{3}$, in particular, is a clear indication of the graphitisation order of the CNFs, since graphite is theoretically composed of solely $\mathrm{sp}^{2}$ hybridised carbons. From Table 1 it is possible to notice that, as expected, increasing the CNFs annealing temperature, the $\mathrm{sp}^{2} / \mathrm{sp}^{3}$ ratio increases, and thus the graphitisation order increases as well. In particular, the amount of $\mathrm{sp}^{2}$ carbon varies from $52 \%$ of the less graphitic CNFs-PS-OX to $82 \%$ of the most graphitic CNFs-HHT.

Table 1. X-ray photoelectron spectroscopy (XPS) and Raman analysis for the evaluation of the graphitisation order.

\begin{tabular}{|c|c|c|c|c|}
\hline Catalyst & $\mathrm{Csp}{ }^{2}(\%)$ & $\mathrm{C} \mathrm{sp}{ }^{3}(\%)$ & $\mathrm{sp}^{2} / \mathrm{sp}^{3}$ & $\mathbf{I}_{\mathbf{D}} / \mathbf{I}_{\mathrm{G}}$ \\
\hline CNFs-PS & n.a. & n.a. & n.a. & 0.75 \\
\hline CNFs-LHT & n.a. & n.a. & n.a. & 0.71 \\
\hline CNFs-HHT & n.a. & n.a. & n.a. & 0.11 \\
\hline Pd/CNFs-PS-OX & 51.8 & 34.6 & 1.5 & n.a. \\
\hline Pd/CNFs-PS & 66.7 & 22.4 & 3.0 & n.a. \\
\hline Pd/CNFs-LHT & 72.0 & 17.4 & 4.1 & n.a. \\
\hline $\mathrm{Pd} / \mathrm{CNFs}-\mathrm{HHT}$ & 82.1 & 7.5 & 10.9 & n.a. \\
\hline
\end{tabular}

Figure 1 shows XPS Pd $3 d$ spectra of the fresh samples. The Pd $3 d_{5 / 2}$ component at ca. $335 \mathrm{eV}$ was assigned to metallic Pd [41], while the component at approximately $337 \mathrm{eV}$ to $\mathrm{Pd}^{2+}$, mainly present as $\mathrm{PdO}$ [42]. As expected, the oxygen-functionalised catalyst (Pd/CNFs-PS-OX) displays a high amount of $\mathrm{Pd}^{2+}$ species. However, no apparent correlation could be detected between the amount of metallic $\mathrm{Pd}$ and the modification in morphology through annealing temperature. From Table 2, it could also be noticed that the experimental metal loadings are lower than the values calculated by EDX. This 
difference is due to the fact that XPS is a surface-sensitive technique, in contrast with the bulk sensitive EDX, and thus cannot detect the presence of metal at a depth greater than ca. $3 \mathrm{~nm}$ [43].

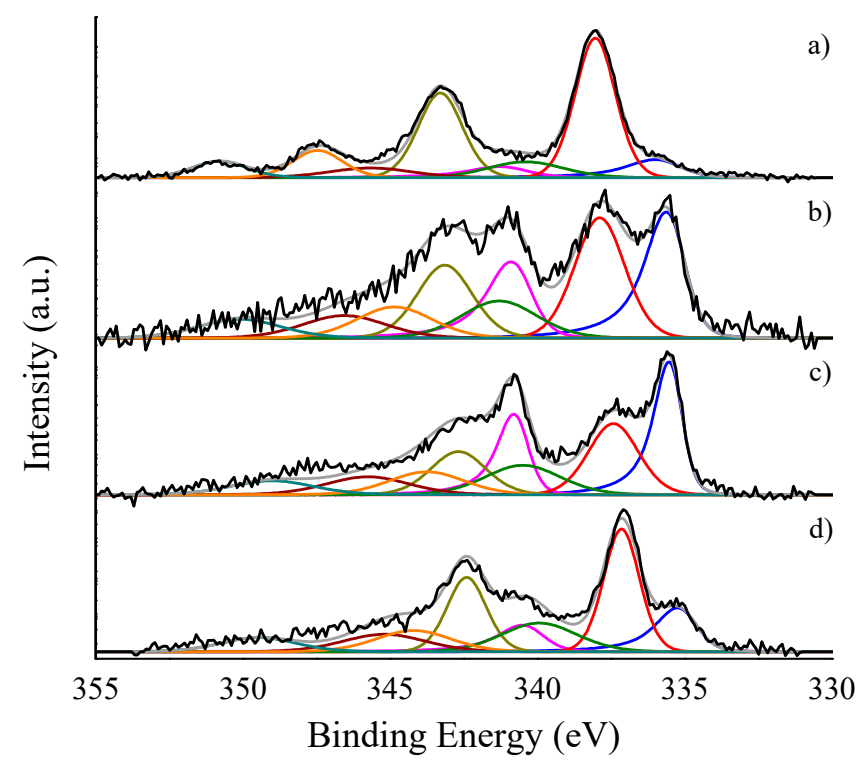

Figure 1. Pd 3d XPS analysis of (a) Pd/CNFs-PS-OX, (b) Pd/CNFs-PS, (c) Pd/CNFs-LHT and (d) $\mathrm{Pd} / \mathrm{CNFs}-\mathrm{HHT}$.

Table 2. Palladium, oxygen and chlorine atomic contents and relative abundance of $\mathrm{Pd}^{0}$ of the four catalysts used.

\begin{tabular}{lcccc}
\hline Catalyst & $\begin{array}{c}\text { Pd Content } \\
\text { (at. \%) }\end{array}$ & $\begin{array}{c}\text { Relative Pd0 } \\
\text { Content (\%) }\end{array}$ & $\begin{array}{c}\text { O Content } \\
\text { (at. \%) }\end{array}$ & $\begin{array}{c}\text { Cl Content } \\
\text { (at. \%) }\end{array}$ \\
\hline Pd/CNFs-PS-OX & 0.75 & 15.6 & 12.05 & 0.04 \\
Pd/CNFs-PS & 0.40 & 58.4 & 2.94 & 0.06 \\
Pd/CNFs-LHT & 0.57 & 59.1 & 2.60 & 0.04 \\
Pd/CNFs-HHT & 0.71 & 25.9 & 0.94 & - \\
\hline
\end{tabular}

The oxygen content was analysed by monitoring the $\mathrm{O} 1 \mathrm{~s}$ peak in the $530-540 \mathrm{eV}$ range and the results are presented in Table 2 and Figure 2. The catalysts which have not been functionalised still present some surface oxygen, in part due to PdO species and in part due to oxygen functionalities formed by exposure of the support to the atmosphere. The oxygen naturally present in the air, in fact, at room temperature can react with carbon atoms of incomplete graphitic layers. As a consequence, increasing the graphitisation order results in a decrease in oxygen content due to the reduction in the number of structural defects that can host functionalisation [44]. Moreover, oxygen can bind to carbon in different ways. The assignment of the $\mathrm{O} 1 \mathrm{~s}$ components is not always elementary, and particular attention must be given. The peak at $530-531.5 \mathrm{eV}$ is generally assigned to $\mathrm{C}=\mathrm{O}$ species, while the one at $534.5-535 \mathrm{eV}$ is relative to carboxylic groups. C-O-H and C-O-C bonds are the most critical species, and opposed opinions have been found in the literature regarding their assignment. However, since hydrogen is slightly less electronegative than carbon, carbon-oxygen bonds in the ether-like group should appear at slightly higher energy than carbon-oxygen bonds in hydroxyl groups, 533.0-533.2 eV and 531.5-531.8 eV respectively. It is interesting to notice that, as expected, the content of $\mathrm{C}-\mathrm{O}$ single bonds decreases with an increase of the CNFs annealing temperature. Finally, the peak at 536.7-537.1 is generally assigned to adsorbed water. 


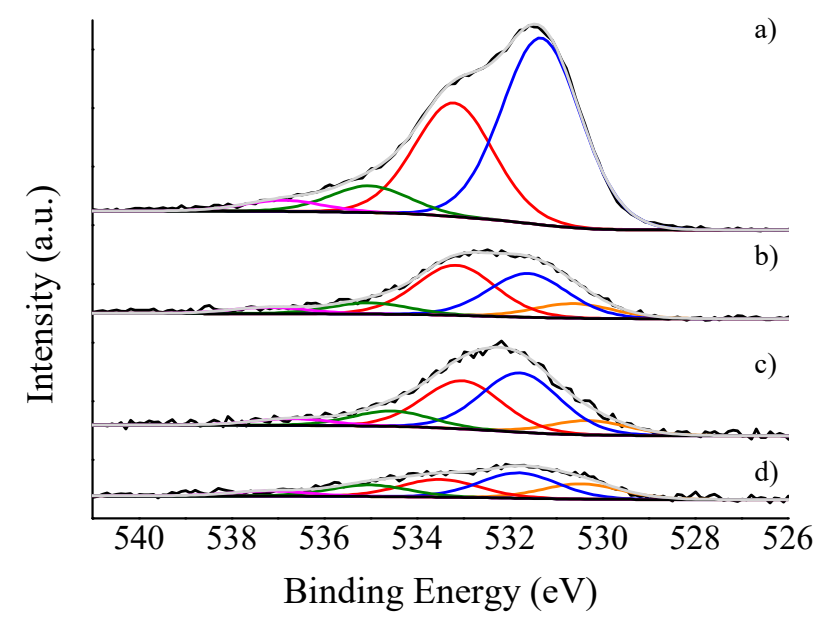

Figure 2. O $1 \mathrm{~s}$ XPS analysis of (a) Pd/CNFs-PS-OX, (b) Pd/CNFs-PS, (c) Pd/CNFs-LHT and (d) $\mathrm{Pd} / \mathrm{CNFs}-\mathrm{HHT}$.

Lastly, the presence of chlorine impurities coming from the Pd precursor was detected by monitoring the $\mathrm{Cl} 2 \mathrm{p}_{3 / 2}$ emission in the binding energy region of 198-199 eV. Cl relative atomic content is reported in Table 2. Very low amount of inorganic chlorine was detected $(<0.06 \%)$ either as chloride anions or chlorine covalently bonded to carbon atoms.

Raman spectroscopy analysis was performed on the bare supports in a wavenumber range of 900-1900 $\mathrm{cm}^{-1}$. This analysis allows for evaluating the structural disorder of the graphitic domains by monitoring the intensity of the peaks at 1348 and $1572 \mathrm{~cm}^{-1}$ (Figure 3) and their relative ratio (Table 1). The two peaks are attributed to the $\mathrm{D}$ and $\mathrm{G}$ bands for $\mathrm{sp}^{2}$ clusters respectively, and they are caused by a disorder in the $\mathrm{sp}^{2}$-hybridised carbon ( $\mathrm{D}$ band) and by the stretching of the $\mathrm{C}-\mathrm{C}$ bonds in the $\mathrm{sp}^{2}$ graphitic domains ( $\mathrm{G}$ band). The ratio $\mathrm{I}_{\mathrm{D}} / \mathrm{I}_{\mathrm{G}}$ is then an index of the structural disorder and thus related to the size of graphitic domains. For the bare supports, as expected, the increase of the annealing temperature causes a decrease of the $\mathrm{I}_{\mathrm{D}} / \mathrm{I}_{\mathrm{G}}$ ratio, with the CNFs-HHT being the most graphitic sample and the CNFs-PS the least graphitic one. This confirms XPS analysis, showing that a higher degree of graphitisation is reached at high pre-treatment temperatures.

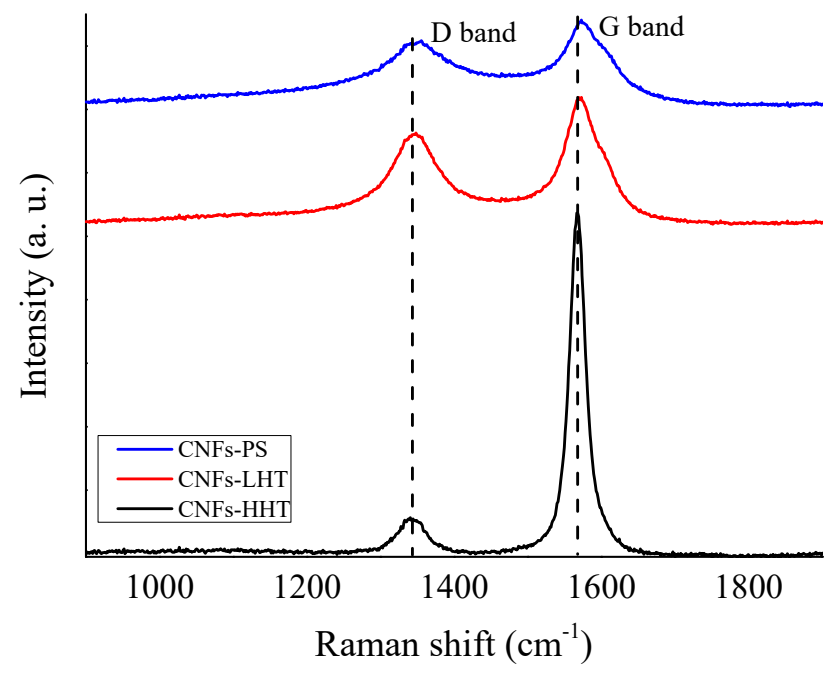

Figure 3. Raman analysis of the CNFs-PS, CNFs-LHT and CNFs-HHT supports.

Nanoparticles dimension and size distribution of the four catalysts were measured from bright field transmission electron microscopy (TEM) micrographs (Table 3 and Figure 4). The particle size distribution ranges from 2.5 to $10 \mathrm{~nm}$, with mean values around $5-7 \mathrm{~nm}$ in all the cases. It is worth 
notice that nanoparticles tend to be slightly smaller when supported on CNFs with a high degree of graphitisation.

Table 3. Particle size and size distribution of the four catalysts before and after reaction. Surface Pd percentage $\left(\mathrm{Pd}_{\mathrm{SURF}}\right)$ is also reported for the fresh catalysts.

\begin{tabular}{cccccc}
\hline \multirow{2}{*}{ Catalyst } & \multicolumn{3}{c}{ Fresh } & \multicolumn{2}{c}{ Used } \\
\cline { 2 - 6 } & Mean $(\mathbf{n m})$ & Std. Dev. $(\mathbf{n m})$ & Pd $_{\text {SURF }}(\mathbf{\%})$ & Mean $\mathbf{( n m )}$ & Std. Dev. (nm) \\
\hline Pd/CNFs-PS-OX & 5.8 & 1.1 & 20.7 & 5.7 & 2.4 \\
Pd/CNFs-PS & 6.9 & 1.8 & 17.6 & 6.8 & 2.0 \\
Pd/CNFs-LHT & 5.7 & 1.3 & 21.1 & 7.5 & 2.8 \\
Pd/CNFs-HHT & 5.4 & 0.9 & 22.1 & 5.9 & 2.3 \\
\hline
\end{tabular}
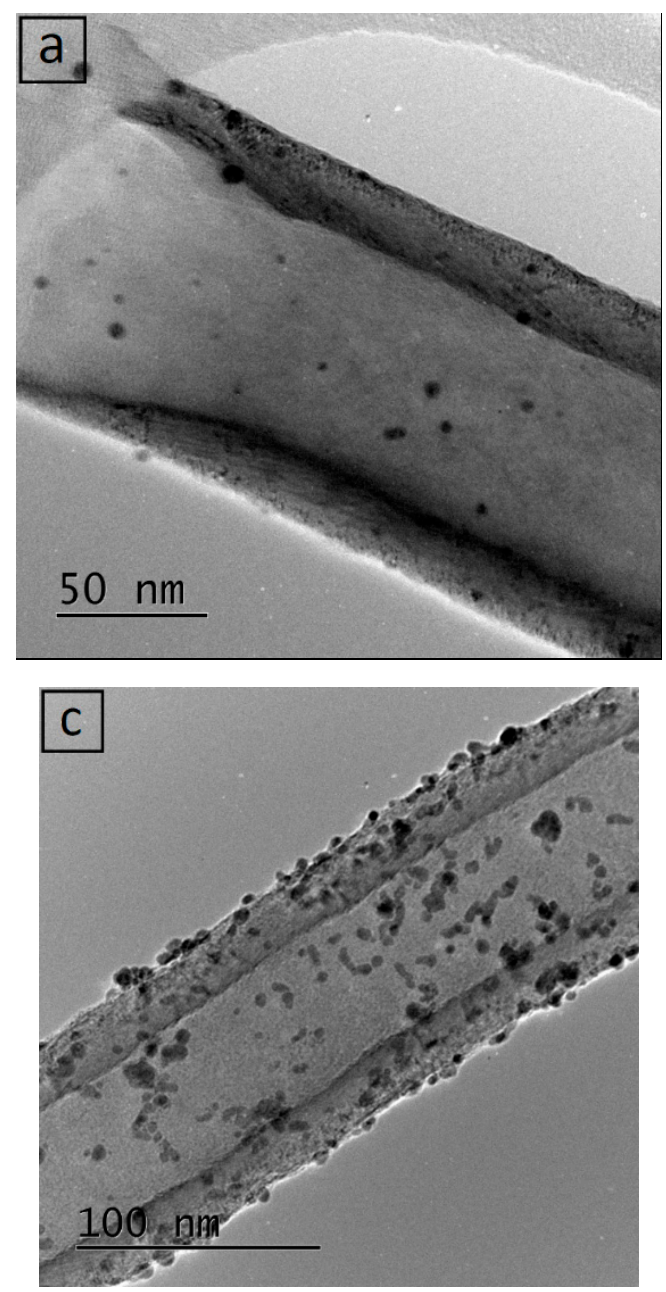
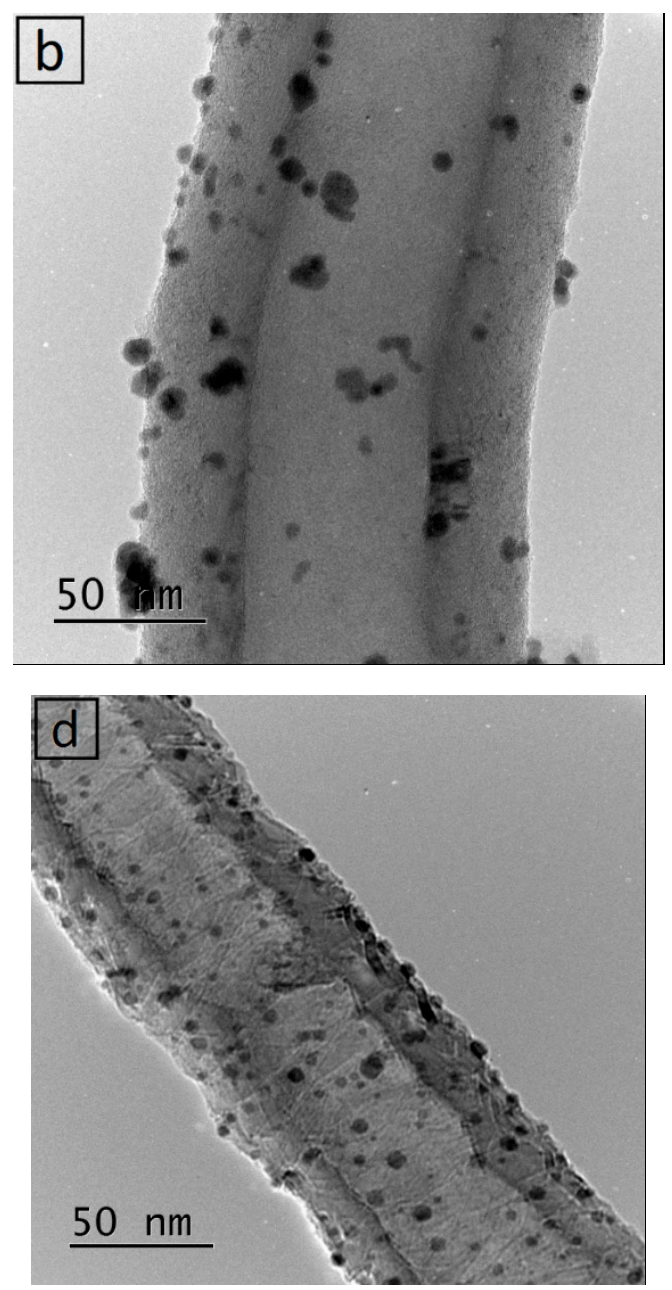

Figure 4. Representative transmission electron microscopy (TEM) micrographs of the four catalysts used before reaction: (a) Pd/CNFs-PS-OX, (b) Pd/CNFs-PS, (c) Pd/CNFs-LHT and (d) Pd/CNFs-HHT.

The total metal loading was finally measured by SEM-EDX. In all the cases, the Pd loading was very close to the theoretical value of $1 \mathrm{wt} \%$ (Table 4). Unlike XPS, EDX is, in fact, a bulk sensitive analysis and thus more accurate in the calculation of the total metal loading. 
Table 4. Pd loading of the four catalysts.

\begin{tabular}{cc}
\hline Catalyst & Pd Loading (wt \%) \\
\hline Pd/CNFs-PS-OX & 1.01 \\
Pd/CNFs-PS & 1.04 \\
Pd/CNFs-LHT & 1.03 \\
Pd/CNFs-HHT & 1.03 \\
\hline
\end{tabular}

\subsection{Cinnamaldehyde Hydrogenation}

Catalytic CAL hydrogenation tests were conducted with the four different catalysts. The scheme of reaction is presented in Figure 5. The products of hydrogenation of the $C=C$ and $C=O$ groups are HCAL and $\mathrm{COH}$ respectively. Further addition of $\mathrm{H}_{2}$ leads to hydrocinnamyl alcohol (HCOH) or to 1-phenylpropane (PPR) by hydrogenolysis mechanism. The hydrogenation activity was evaluated in terms of Turnover Frequency (TOF) considering both the total Pd content $\left(\mathrm{TOF}_{\mathrm{TOT}}\right.$ ) and on the surface atoms only ( $\left.\mathrm{TOF}_{\mathrm{SURF}}\right)$. TOF calculation is reported in the Supplementary Information.

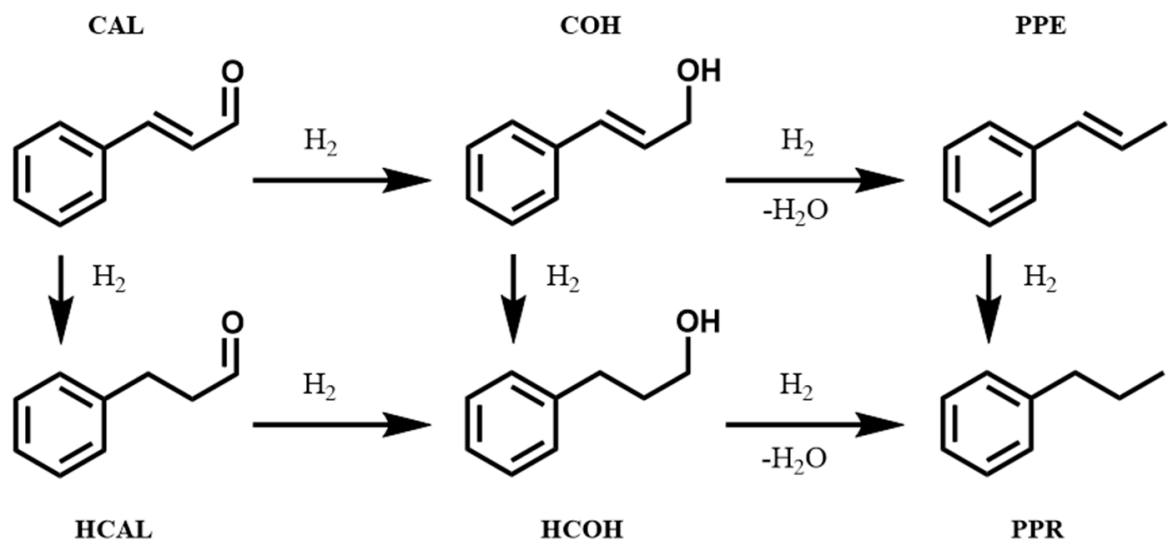

Figure 5. Scheme of the possible products of cinnamaldehyde (CAL) hydrogenation: cinnamyl alcohol $(\mathrm{COH})$, hydrocinnamaldehyde (HCAL), hydrocinnamyl alcohol (HCOH), 1-phenyl-1-propene (PPE) and 1-phenylpropane (PPR).

Recent studies reported an increase in selectivity towards HCAL with a consequent increase in activity when either Ru, Pt or Pd were supported on low-oxygen content CNFs [24,26,45]. In agreement with those studies, highest activity in the CAL hydrogenation was reached when CNFs-HHT was used as support (Table 5), with a TOF 3 times higher than the Pd/CNFs-PS catalyst (from 2126 to $6776 \mathrm{~s}^{-1}$ ). Unexpectedly, however, the support with the highest oxygen content (CNFs-PS-OX) was not the least active. We ascribed the low activity of the Pd/CNFs-PS catalyst to the presence of big metal nanoparticles compared to the other catalysts. It has been previously reported, in fact, that large metal nanoparticles are less active due to a change in the adsorption mode. Moreover, in our case, the increase in activity is not related to the increase in the hydrogenation rate of the $\mathrm{C}=\mathrm{C}$ bond only. With the decrease of surface oxygen, in fact, the selectivity towards CAL decrease from $80 \%$ with the Pd/CNFs-PS-OX to $68 \%$ when CNFs-HHT was used as support, with a consequent increase in selectivity mainly towards the $\mathrm{HCOH}$. It is well known that Pd preferentially adsorbs and hydrogenates the $\mathrm{C}=\mathrm{C}$ double bond. The presence of polar oxygen surface atoms avoids the adsorption of the benzene ring on the carbon surface, thus inhibiting the participation of the peripheral atoms in the hydrogenation. With the increase of annealing temperature, the oxygen content decreases, making the carbon surface available for the adsorption of aromatic groups. With more adsorption sites, the overall hydrogenation activity increases. This, however, greatly enhances the hydrogenation of the carbonylic group due to the better accessibility of the $\mathrm{C}=\mathrm{O}$ bond rather than the $\mathrm{C}=\mathrm{C}$ bond, thus increasing the overall production of $\mathrm{HCOH}$ (Table 5). It is worth notice how the presence of acidic oxygen functional 
groups activates the hydrogenolysis mechanism to form 1-phenylpropane. The plot conversion as a function of time of the four catalysts is reported in Figure S1 in the Supplementary Information.

Table 5. Catalytic data for the cinnamaldehyde hydrogenation reaction. Reaction conditions: $25^{\circ} \mathrm{C}$, 1 bar $\mathrm{H}_{2}, 0.3 \mathrm{~mol} \mathrm{~L}^{-1}$ cinnamaldehyde in p-xylene, substrate: metal molar ratio 1:1000. TOF calculated at $5 \mathrm{~min}$ of reaction.

\begin{tabular}{|c|c|c|c|c|c|c|c|}
\hline \multirow{2}{*}{ Catalyst } & \multirow{2}{*}{$\begin{array}{c}\text { Conversion (\%) } \\
\text { at } 5 \mathrm{Min}\end{array}$} & \multirow{2}{*}{$\begin{array}{c}\text { TOF }_{\text {TOT }} \\
\quad\left(\mathbf{s}^{-1}\right)\end{array}$} & \multirow{2}{*}{$\begin{array}{c}\text { TOF } \\
\left(\mathrm{s}^{-1}\right)\end{array}$} & \multicolumn{4}{|c|}{ Selectivity at $90 \%$ Conversion $(\%)$} \\
\hline & & & & HCAL & $\mathrm{HCOH}$ & PPR & $\mathrm{COH}$ \\
\hline Pd/CNFs-PS-OX & 5 & 625 & 3015 & 80 & 3 & 15 & - \\
\hline Pd/CNFs-PS & 2 & 375 & 2126 & 83 & 10 & 6 & - \\
\hline Pd/CNFs-LHT & 8 & 1000 & 4747 & 76 & 22 & - & - \\
\hline $\mathrm{Pd} / \mathrm{CNFs}-\mathrm{HHT}$ & 12 & 1500 & 6776 & 68 & 30 & 1 & - \\
\hline
\end{tabular}

The effect of reaction temperature on the catalytic hydrogenation of CAL was evaluated using CNFs-HHT as support (Table 6). Increasing the temperature from 25 to $100{ }^{\circ} \mathrm{C}$, the overall activity enhanced by a factor of 16 (from 6776 to $109,862 \mathrm{~s}^{-1}$ ). The reaction temperature seems to affect more the hydrogenation of the $\mathrm{C}=\mathrm{O}$ bond, with an increase in selectivity towards $\mathrm{HCOH}$ from 30 to $44 \%$. Interestingly, $\mathrm{COH}$ was produced both at 60 and $100{ }^{\circ} \mathrm{C}$, confirming the increase in the carbonyl hydrogenation rate at high temperatures.

Table 6. Catalytic data for the cinnamaldehyde hydrogenation reaction with Pd/CNFs-HHT at different reaction temperatures. Reaction conditions: 1 bar $\mathrm{H}_{2}, 0.3 \mathrm{~mol} \mathrm{~L}^{-1}$ cinnamaldehyde in p-xylene, substrate: metal molar ratio 1:1000. TOF calculated at 5 min of reaction.

\begin{tabular}{|c|c|c|c|c|c|c|}
\hline \multirow{2}{*}{$\begin{array}{c}\text { Temperature } \\
\left({ }^{\circ} \mathrm{C}\right)\end{array}$} & \multirow{2}{*}{$\begin{array}{c}\text { TOF }_{\text {TOT }} \\
\left(\mathrm{s}^{-1}\right)\end{array}$} & \multirow{2}{*}{$\begin{array}{c}\text { TOF }_{\text {SURF }} \\
\left(\mathrm{s}^{-1}\right)\end{array}$} & \multicolumn{4}{|c|}{ Selectivity at $90 \%$ Conversion (\%) } \\
\hline & & & HCAL & $\mathrm{HCOH}$ & PPR & $\mathrm{COH}$ \\
\hline 25 & 1500 & 6776 & 68 & 30 & 1 & - \\
\hline 60 & 12,500 & 56,467 & 58 & 33 & 2 & 6 \\
\hline 100 & 24,320 & 109,862 & 41 & 44 & 3 & 10 \\
\hline
\end{tabular}

Reusability tests of the Pd/CNFs-HHT catalyst were carried out simply by centrifugation and filtration of the reaction mixture after $2 \mathrm{~h}$ of reaction. After the first use, a slight decrease in activity was observed, specifically from $98 \%$ to $89 \%$ (Figure 6). The conversion, however, remained constant for the following reuses, demonstrating the high reusability capacity of the Pd/CNFs-HHT catalyst. This is probably due to the strong interaction between the metal nanoparticles and the support that prevents any sintering phenomena, as confirmed by electron microscopy (Table 3). XPS analysis was performed on the used catalyst to evaluate the Pd oxidation state and compared with the fresh one (Figure 7). Interestingly, all the Pd in the used catalyst is in the metallic state. This is not surprising since the presence of dissolved hydrogen in the reaction solvent can reduce the passivated Pd layer to metallic Pd. 


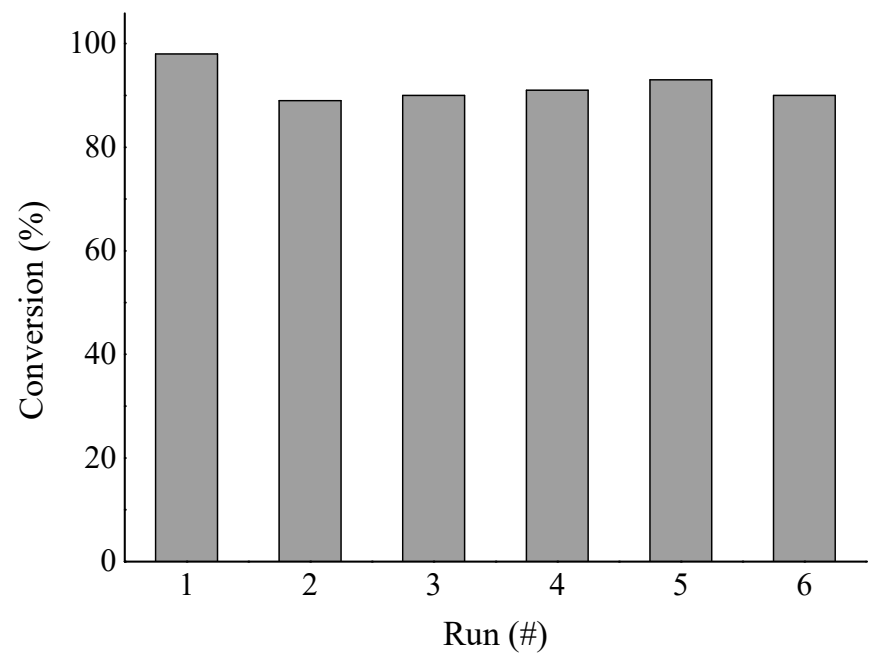

Figure 6. Reusability of the Pd/CNFs-HHT catalyst in the cinnamaldehyde hydrogenation reaction. Reaction conditions: $25^{\circ} \mathrm{C}, 1$ bar $\mathrm{H}_{2}, 0.3 \mathrm{~mol} \mathrm{~L}^{-1}$ cinnamaldehyde in p-xylene, substrate: metal molar ratio 1:1000. Time of reaction $90 \mathrm{~min}$.

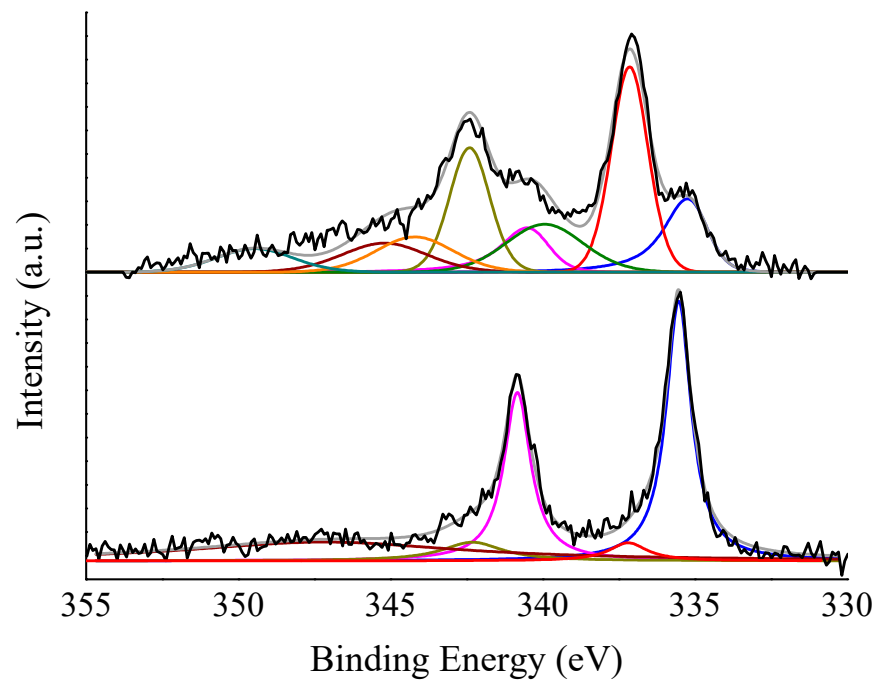

Figure 7. XPS analysis of the Pd/CNFs-HHT catalyst before (top) and after (bottom) reaction.

\subsection{Cinnamyl Alcohol Dehydrogenation}

The performance of the Pd nanoparticles supported on different CNFs has been tested also on the cinnamyl alcohol dehydrogenation reaction in an inert nitrogen atmosphere. The main products of the reaction are cinnamaldehyde (CAL), hydrocinnamyl alcohol (HCOH) and 1-phenyl-1-propene (PPE), although further side products can potentially be formed, such as hydrocinnamaldehyde (HCAL) and 1-phenylpropane (PPR) (Figure 8). As per the CAL hydrogenation, the catalytic activity seems to be related to both surface oxygen content and nanoparticles dimension, with the Pd/CNFs-HHT being the most active (TOF $6144 \mathrm{~s}^{-1}$ ). In all the cases, the main product was CAL, with $\mathrm{HCOH}$ and PPE as side products. Only a very small amount of PPR and HCAL were detected in the reaction mixture (reported as "others" in Table 7). It is interesting to notice that the product selectivity, at $90 \%$ iso-conversion, is mainly influenced by the presence of oxygen functionalities. A decrease in the oxygen content, in fact, results in an increase in CAL production from $52 \%$ with Pd/CNFs-PS-OX to $70 \%$ with Pd/CNFs-HHT. A similar trend was observed with $\mathrm{HCOH}$, confirming that in an inert atmosphere and in the absence of oxygen functionalities the disproportion mechanism is favoured. With the increase of acidic surface groups, however, the hydrogenolysis mechanism starts to become 
evident, as suggested by the increase in PPE selectivity from $9 \%$ with the Pd/CNFs-HHT to $24 \%$ with the Pd/CNFs-PS-OX. The plot of conversion as a function of time of the four catalysts is reported in Figure $\mathrm{S} 2$ in the Supplementary Information.

PPE

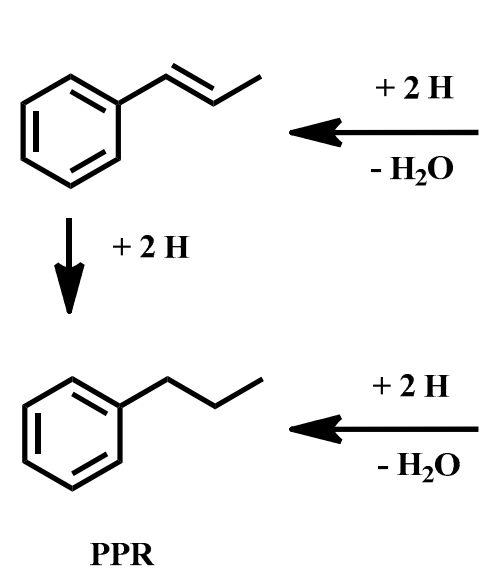

$\mathrm{COH}$<smiles>OC/C=C/c1ccccc1</smiles>

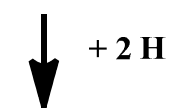<smiles>OCCCc1ccccc1</smiles>

$\mathrm{HCOH}$
CAL

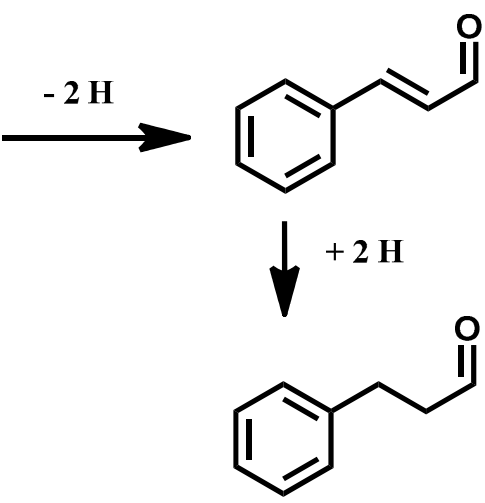

HCAL

Figure 8. Scheme of the possible products of cinnamyl alcohol $(\mathrm{COH})$ dehydrogenation: cinnamaldehyde (CAL), hydrocinnamaldehyde (HCAL), hydrocinnamyl alcohol (HCOH), 1-phenyl-1-propene (PPE) and 1-phenylpropane (PPR).

Table 7. Catalytic data for the cinnamyl alcohol dehydrogenation reaction. Reaction conditions: $100{ }^{\circ} \mathrm{C}$, 3 bar $\mathrm{N}_{2}, 0.3 \mathrm{~mol} \mathrm{~L}^{-1}$ cinnamyl alcohol in p-xylene, substrate: metal molar ratio 1:500. TOF calculated at $5 \mathrm{~min}$ of reaction.

\begin{tabular}{|c|c|c|c|c|c|c|c|}
\hline \multirow{2}{*}{ Catalyst } & \multirow{2}{*}{$\begin{array}{c}\text { Conversion }(\%) \\
\text { at } 5 \mathrm{Min}\end{array}$} & \multirow{2}{*}{$\begin{array}{l}\text { TOF }_{\text {TOT }} \\
\left(\mathrm{s}^{-1}\right)\end{array}$} & \multirow{2}{*}{$\begin{array}{c}\text { TOF }_{\text {SURF }} \\
\left(\mathrm{s}^{-1}\right)\end{array}$} & \multicolumn{4}{|c|}{ Selectivity at $90 \%$ Conversion $(\%)$} \\
\hline & & & & CAL & $\mathrm{HCOH}$ & PPE & Others \\
\hline Pd/CNFs-PS-OX & 4 & 680 & 3280 & 52 & 12 & 24 & 12 \\
\hline Pd/CNFs-PS & 2 & 440 & 2494 & 58 & 17 & 15 & 10 \\
\hline Pd/CNFs-LHT & 5 & 720 & 3418 & 63 & 23 & 9 & 5 \\
\hline Pd/CNFs-HHT & 9 & 1360 & 6144 & 70 & 20 & 9 & 1 \\
\hline
\end{tabular}

\section{Conclusions}

Four carbon nanofiber samples with different surface oxygen content and graphitisation order were used as support for Pd nanoparticles. The catalysts were fully characterised with XPS and Raman to evaluate their surface properties and Pd oxidation state, while TEM and EDX evaluated metal nanoparticles dimension and total metal loading. A more graphitic surface and a lower oxygen content are correlated with an increase in the annealing temperature during the preparation of the CNFs. Moreover, smaller Pd nanoparticles were formed on the low-oxygenated supports. The catalysts were tested in the cinnamaldehyde hydrogenation reaction and the reverse cinnamyl alcohol dehydrogenation. In both cases, a decrease in nanoparticle dimensions and oxygen content resulted in an increase in overall activity, from 2126 to $6776 \mathrm{~s}^{-1}$ in the CAL hydrogenation and from 2494 to $6144 \mathrm{~s}^{-1}$ for the $\mathrm{COH}$ dehydrogenation. Contrary to what has been reported in the literature, however, we showed an increase in $\mathrm{C}=\mathrm{O}$ hydrogenation with a decrease in surface oxygen content. We ascribed this effect to the better accessibility of specific peripheral metal atoms when functional groups are not present on the support surface. The most active catalyst (Pd/CNFs-HHT) was tested for multiple consecutive reactions showing good reusability, with a small loss of activity only after the first use (form $98 \%$ to $89 \%$ of conversion). Finally, we demonstrated how the chemistry surface of CNFs can affect the cinnamyl alcohol dehydrogenation reaction as well, showing that activity increases with 
decreasing the nanoparticle dimension, while selectivity towards CAL increases decreasing surface oxygen content.

Supplementary Materials: The following are available online at http://www.mdpi.com/2076-3417/9/23/5061/s1, Figure S1: Time on line conversion of the four catalysts in the cinnamaldehyde hydrogenation reaction. Figure S2: Time on line conversion of the four catalysts in the cinnamyl alcohol dehydrogenation reaction.

Author Contributions: S.C. wrote the article, synthesized the catalysts and carried out catalytic evaluation. F.J.S.T. carried out XPS, Raman and TEM analysis and helped with the interpretation. N.D. and A.V. designed the experiments and were involved in the writing and editing of the manuscript.

Funding: This research received no external funding.

Conflicts of Interest: The authors declare no conflict of interest.

\section{References}

1. Edison, T.A. Manufacture of Carbon Filaments. U.S. Patent US484185A, 11 October 1892.

2. Iijima, S. Helical microtubules of graphitic carbon. Nature 1991, 354, 56-58. [CrossRef]

3. Coelho, N.M.A.; Furtado, J.L.B.; Pham-Huu, C.; Vieira, R. Carbon Nanofibers: A Versatile Catalytic Support. Mater. Res. 2008, 11, 353-357. [CrossRef]

4. Feng, L.; Xie, N.; Zhong, J. Carbon nanofibers and their composites: A review of synthesizing, properties and applications. Materials 2014, 7, 3919-3945. [CrossRef] [PubMed]

5. De Jong, K.P.; Geus, J.W. Carbon Nanofibers: Catalytic Synthesis and Applications. Catal. Rev. Sci. Eng. 2000, 42, 481-510. [CrossRef]

6. Al-Saleh, M.H.; Sundararaj, U. Review of the mechanical properties of carbon nanofiber/polymer composites. Compos. Part A Appl. Sci. Manuf. 2011, 42, 2126-2142. [CrossRef]

7. Serp, P.; Corrias, M.; Kalck, P. Carbon nanotubes and nanofibers in catalysis. Appl. Catal. A Gen. 2003, 253, 337-358. [CrossRef]

8. Cattaneo, S.; Naslhajian, H.; Somodi, F.; Evangelisti, C.; Villa, A.; Prati, L. Ruthenium on carbonaceous materials for the selective hydrogenation of HMF. Molecules 2018, 23, 2007. [CrossRef]

9. Villa, A.; Wang, D.; Chan-Thaw, C.E.; Campisi, S.; Veith, G.M.; Prati, L. The confinement effect on the activity of Au NPs in polyol oxidation. Catal. Sci. Technol. 2016, 6, 598-601. [CrossRef]

10. Pan, X.; Fan, Z.; Chen, W.; Ding, Y.; Luo, H.; Bao, X. Enhanced ethanol production inside carbon-nanotube reactors containing catalytic particles. Nat. Mater. 2007, 6, 507-511. [CrossRef]

11. Jouve, A.; Cattaneo, S.; Capelli, S.; Stucchi, M.; Evangelisti, C.; Villa, A.; Prati, L. CNF-Functionalization as Versatile Tool for Tuning Activity in Cellulose-Derived Product Hydrogenation. Molecules 2019, $24,316$. [CrossRef]

12. Testolin, A.; Cattaneo, S.; Wang, W.; Wang, D.; Pifferi, V.; Prati, L.; Falciola, L.; Villa, A. Cyclic Voltammetry Characterization of $\mathrm{Au}, \mathrm{Pd}$, and AuPd Nanoparticles Supported on Different Carbon Nanofibers. Surfaces 2019, 2, 16. [CrossRef]

13. Campisi, S.; Chan-Thaw, C.; Villa, A. Understanding Heteroatom-Mediated Metal-Support Interactions in Functionalized Carbons: A Perspective Review. Appl. Sci. 2018, 8, 1159. [CrossRef]

14. Delgado, J.J.; Vieira, R.; Rebmann, G.; Su, D.S.; Keller, N.; Ledoux, M.J.; Schlögl, R. Supported carbon nanofibers for the fixed-bed synthesis of styrene. Carbon 2006, 44, 809-812. [CrossRef]

15. Chambers, A.; Nemes, T.; Rodriguez, N.M.; Baker, R.T.K. Catalytic Behavior of Graphite Nanofiber Supported Nickel Particles. 1. Comparison with Other Support Media. J. Phys. Chem. B 2002, 102, 2251-2258. [CrossRef]

16. Xue, Z.; Ma, M.G.; Li, Z.; Mu, T. Advances in the conversion of glucose and cellulose to 5-hydroxymethylfurfural over heterogeneous catalysts. RSC Adv. 2016, 6, 98874-98892. [CrossRef]

17. Kohlpaintner, C.; Schulte, M.; Falbe, J.; Lappe, P.; Weber, J. Aldehydes, Araliphatic. Ullmann's Encycl. Ind. Chem. 2005. [CrossRef]

18. Konno, K.; Sakagami, H.; Kawazoe, Y.; Yamamoto, N. AIDS Therapeutic Agents Comprising Polymers Formed from Cinnamic Acid Derivatives. U.S. Patent US5632980A, 27 May 1997.

19. Gallezot, P.; Richard, D. Selective Hydrogenation of $\alpha, \beta$-Unsaturated Aldehydes. Catal. Rev. 1998, 41, 26. [CrossRef] 
20. Cattaneo, S.; Freakley, S.J.; Morgan, D.J.; Sankar, M.; Dimitratos, N.; Hutchings, G.J. Cinnamaldehyde hydrogenation using Au-Pd catalysts prepared by sol immobilisation. Catal. Sci. Technol. 2018, 8, 1677-1685. [CrossRef]

21. Rao, R.G.; Blume, R.; Hansen, T.W.; Fuentes, E.; Dreyer, K.; Moldovan, S.; Ersen, O.; Hibbitts, D.D.; Chabal, Y.J.; Schlögl, R.; et al. Interfacial charge distributions in carbon-supported palladium catalysts. Nat. Commun. 2017, 8, 340. [CrossRef]

22. Nagpure, A.S.; Gurrala, L.; Gogoi, P.; Chilukuri, S.V. Hydrogenation of cinnamaldehyde to hydrocinnamaldehyde over Pd nanoparticles deposited on nitrogen-doped mesoporous carbon. RSC Adv. 2016, 6, 44333-44340. [CrossRef]

23. Ji, X.; Niu, X.; Li, B.; Han, Q.; Yuan, F.; Zaera, F.; Zhu, Y.; Fu, H. Selective Hydrogenation of Cinnamaldehyde to Cinnamal Alcohol over Platinum/Graphene Catalysts. ChemCatChem 2014, 6, 3246-3253. [CrossRef]

24. Pham-Huu, C.; Keller, N.; Ledoux, M.J.; Charbonniere, L.J.; Ziessel, R. Carbon nanofiber supported palladium catalyst for liquid-phase reactions. An active and selective catalyst for hydrogenation of $\mathrm{C}=\mathrm{C}$ bonds. Chem. Commun. 2000, 170, 1871-1872. [CrossRef]

25. Toebes, M.L.; Prinsloo, F.F.; Bitter, J.H.; Van Dillen, A.J.; De Jong, K.P. Influence of oxygen-containing surface groups on the activity and selectivity of carbon nanofiber-supported ruthenium catalysts in the hydrogenation of cinnamaldehyde. J. Catal. 2003, 214, 78-87. [CrossRef]

26. Toebes, M.L.; Zhang, Y.; Hájek, J.; Alexander Nijhuis, T.; Bitter, J.H.; Jos Van Dillen, A.; Murzin, D.Y.; Koningsberger, D.C.; De Jong, K.P. Support effects in the hydrogenation of cinnamaldehyde over carbon nanofiber-supported platinum catalysts: Characterization and catalysis. J. Catal. 2004, 226, 215-225. [CrossRef]

27. Plomp, A.J.; Vuori, H.; Krause, A.O.I.; de Jong, K.P.; Bitter, J.H. Particle size effects for carbon nanofiber supported platinum and ruthenium catalysts for the selective hydrogenation of cinnamaldehyde. Appl. Catal. A Gen. 2008, 351, 9-15. [CrossRef]

28. Grunwaldt, J.-D.; Keresszegi, C.; Mallat, T.; Baiker, A. In situ EXAFS study of Pd/A12O3 during aerobic oxidation of cinnamyl alcohol in an organic solvent. J. Catal. 2003, 213, 291-295. [CrossRef]

29. Lee, A.F.; Wilson, K. Structure-reactivity correlations in the selective aerobic oxidation of cinnamyl alcohol: In situ XAFS. Green Chem. 2004, 6, 37-42. [CrossRef]

30. Mallat, T.; Bodnar, Z.; Hug, P.; Baiker, A. Selective Oxidation of Cinnamyl Alcohol to Cinnamaldehyde with Air over Bi-Pt/Alumina Catalysts. J. Catal. 1995, 153, 131-143. [CrossRef]

31. Guo, Z.; Liu, B.; Zhang, Q.; Deng, W.; Wang, Y.; Yang, Y. Recent advances in heterogeneous selective oxidation catalysis for sustainable chemistry. Chem. Soc. Rev. 2014, 43, 3480-3524. [CrossRef]

32. Davis, S.E.; Ide, M.S.; Davis, R.J. Selective oxidation of alcohols and aldehydes over supported metal nanoparticles. Green Chem. 2013, 15, 17-45. [CrossRef]

33. Rucinska, E.; Miedziak, P.J.; Pattisson, S.; Brett, G.L.; Iqbal, S.; Morgan, D.J.; Sankar, M.; Hutchings, G.J. Cinnamyl alcohol oxidation using supported bimetallic Au-Pd nanoparticles: An investigation of autoxidation and catalysis. Catal. Sci. Technol. 2018, 8, 2987-2997. [CrossRef]

34. Wu, G.; Brett, G.L.; Cao, E.; Constantinou, A.; Ellis, P.; Kuhn, S.; Hutchings, G.J.; Bethell, D.; Gavriilidis, A. Oxidation of cinnamyl alcohol using bimetallic $\mathrm{Au}-\mathrm{Pd} / \mathrm{TiO} 2$ catalysts: A deactivation study in a continuous flow packed bed microreactor. Catal. Sci. Technol. 2016, 6, 4749-4758. [CrossRef]

35. Corma, A.; Garcia, H.; Leyva, A. Catalytic activity of palladium supported on single wall carbon nanotubes compared to palladium supported on activated carbon: Study of the Heck and Suzuki couplings, aerobic alcohol oxidation and selective hydrogenation. J. Mol. Catal. A Chem. 2005, 230, 97-105. [CrossRef]

36. Parlett, C.M.A.; Durndell, L.J.; Machado, A.; Cibin, G.; Bruce, D.W.; Hondow, N.S.; Wilson, K.; Lee, A.F. Alumina-grafted SBA-15 as a high performance support for Pd-catalysed cinnamyl alcohol selective oxidation. Catal. Today 2014, 229, 46-55. [CrossRef]

37. Mori, S.; Takubo, M.; Makida, K.; Yanase, T.; Aoyagi, S.; Maegawa, T.; Monguchi, Y.; Sajiki, H. A simple and efficient oxidation of alcohols with ruthenium on carbon. Chem. Commun. 2009, 5159-5161. [CrossRef] [PubMed]

38. Durndell, L.J.; Parlett, C.M.A.; Hondow, N.S.; Wilson, K.; Lee, A.F. Tunable Pt nanocatalysts for the aerobic selox of cinnamyl alcohol. Nanoscale 2013, 5, 5412-5419. [CrossRef] 
39. Tessonnier, J.P.; Rosenthal, D.; Hansen, T.W.; Hess, C.; Schuster, M.E.; Blume, R.; Girgsdies, F.; Pfänder, N.; Timpe, O.; Su, D.S.; et al. Analysis of the structure and chemical properties of some commercial carbon nanostructures. Carbon 2009, 47, 1779-1798. [CrossRef]

40. Prati, L.; Villa, A.; Arrigo, R.; Wang, D.; Su, D.S. Gold catalyzed liquid phase oxidation of alcohol: The issue of selectivity. Faraday Discuss. 2011, 152, 353-365. [CrossRef]

41. Militello, M.C.; Simko, S.J. Elemental Palladium by XPS. Surf. Sci. Spectra 1994, 3, 387-394. [CrossRef]

42. Militello, M.C.; Simko, S.J. Palladium Oxide (PdO) by XPS. Surf. Sci. Spectra 1994, 3, 395-401. [CrossRef]

43. Pattamakomsan, K.; Suriye, K.; Dokjampa, S.; Mongkolsiri, N.; Praserthdam, P.; Panpranot, J. Effect of mixed $\mathrm{Al} 2 \mathrm{O} 3$ structure between $\theta$ - and $\alpha-\mathrm{Al} 2 \mathrm{O} 3$ on the properties of $\mathrm{Pd} / \mathrm{Al} 2 \mathrm{O} 3$ in the selective hydrogenation of 1,3-butadiene. Catal. Commun. 2010, 11,311-316. [CrossRef]

44. Serp, P.; Figueiredo, J.L. Carbon Materials for Catalysis; John Wiley \& Sons, Inc.: Hoboken, NJ, USA, 2009; ISBN 9780470178850.

45. Tessonnier, J.P.; Pesant, L.; Ehret, G.; Ledoux, M.J.; Pham-Huu, C. Pd nanoparticles introduced inside multi-walled carbon nanotubes for selective hydrogenation of cinnamaldehyde into hydrocinnamaldehyde. Appl. Catal. A Gen. 2005, 288, 203-210. [CrossRef]

(C) 2019 by the authors. Licensee MDPI, Basel, Switzerland. This article is an open access article distributed under the terms and conditions of the Creative Commons Attribution (CC BY) license (http://creativecommons.org/licenses/by/4.0/). 